\title{
Antihyperglycemic Activity of Vernonia amygdalina Leaf Extracts, Hibiscus esculentus Fruit Extract and Garcinia kola Seed Extract from Kisangani Plants
}

\author{
Frederick M. Katemo ${ }^{1}$, Roland D. Marini ${ }^{1}$ and Justin N. Kadima ${ }^{2 \star}$ \\ ${ }^{1}$ Department of Pharmacy, Faculty of Medicine and Pharmacy, University of Kisangani, DR Congo. \\ ${ }^{2}$ Department of Pharmacy, School of Medicine and Pharmacy, University of Rwanda, Rwanda.
}

Authors' contributions

This work was carried out in collaboration between all authors. Author FMK designed the study, wrote the protocol and wrote the first draft of the manuscript. Authors RDM and JNK managed the analyses of the study. Author JNK managed the literature searches and performed the statistical analysis. All authors read and approved the final manuscript.

Article Information

DOI: $10.9734 / J P R I / 2018 / 40667$

Editor(s):

(1) Jinyong Peng, Professor, College of Pharmacy, Dalian Medical University, Dalian, China.

Reviewers:

(1) Paula Mendonça Leite, Universidade Federal de Minas Gerais, \& Centro Universitário UNA, Brazil.

(2) Bhaskar Sharma, School of Sciences, Suresh Gyan Vihar University, India. Complete Peer review History: http://www.sciencedomain.org/review-history/23825

Original Research Article

Received $8^{\text {th }}$ January 2018

Accepted $21^{\text {st }}$ March 2018

Published 26 ${ }^{\text {th }}$ March 2018

\begin{abstract}
Objective: Many plants used in traditional medicine still need to be studied scientifically in order to verify their medical usefulness and standardize their pharmaceutical properties. The present study aimed at evaluating the antihyperglycemic activity of aqueous and alcoholic extracts from local species of Vernonia amygdalina Delile (Va), Hibiscus esculentus (He) and Garcinia kola Heckel (Gk).

Methods: The tests were done on Va-aqueous, Va-ethanolic, Va-butanolic and Va-saponin leaf extracts; He-aqueous fruit extract and Gk-aqueous seed extract. The extracts were prepared using conventional methods. The activity was evaluated in male rabbits given orally $100 \mathrm{mg}$ of extracts per $\mathrm{Kg} \mathrm{BW}$ and overloaded with glucose $(4 \mathrm{~g} / \mathrm{Kg}) 30$ minutes later. Glibenclamide $0.2 \mathrm{mg} / \mathrm{Kg}$ was given as reference positive control. A negative control group of untreated animals was also included. Blood samples were collected on the animal ear at different times. The assay was performed using a handheld Glucometer ${ }^{\circ}$.
\end{abstract}


Results: The percentages of reduction in glycemia calculated on the basis of the negative control values were $60.5 \%$ for glibenclamide, $70.5 \%$ for Va-ethanol, $57.6 \%$ for Va-aqueous, $42.2 \%$ for Vabutanol, $54.5 \%$ for He-aqueous and $58.7 \%$ for Gk-aqueous. Va-saponins fraction was inactive; it increased the baseline glycemia instead of reducing.

Conclusion: All extracts have a relative reduction activity comparable to glibenclamide with the exception of Va-saponins. Improved tradimedicines can be prepared with ethanolic or polyphenolic dry extracts.

Keywords: Vernonia amygdalina; Hibiscus esculentus; Garcinia kola; antihyperglycemic activity; rabbit.

\section{INTRODUCTION}

Diabetes mellitus (DM) is a metabolic disease characterized by a chronic elevated blood sugar (hyperglycemia). DM is widespread throughout the world both in developed and in developing countries. Globally, an estimated 422 million adults are living with DM according to the latest 2016 data [1]. Despite the progress in the discovery of new therapeutic molecules, DM and its complications still constitute a challenge for the management of patients [2]. Modern drugs, including insulin and oral hypoglycemic agents are costly and have some level of toxicity and adverse drug reactions such as skin rash and low blood sugar by sulfonylureas, kidney complication and dizziness by biguanides, risk of liver disease and anemia by thiazolidinediones. In developing countries, some people don't have easy access to modern antidiabetic medicines and in place recourse to herbal therapy [3]. Recently, some clinical studies have come up with the observation that a complementary therapy with plant extracts may optimize the treatment of DM [4,5]. For example, charantine isolated from the fruit of Momordica charantia has been found more active than tolbutamide [6]; ginsenoside isolated from Asian ginseng root and diosgenin isolated from Trigonella foenumgraecum have been shown to be highly effective against experimental diabetes $[7,8]$.

Vernonia amygdalina of Asteraceae family, Hibiscus esculentus of Malvaceae family and Garcinia kola tree of Clusiaceae family are among widespread plants used against diabetes in traditional medicine in tropical Africa. These plants are invested with many other therapeutic virtues for which they are used in folk medicine. From Vernonia species, a number of biologicallyactive compounds have been isolated including saponins, alkaloids, terpenes, steroids, coumarins, flavonoids, phenolic acids, lignans, xanthones, anthraquinones, edotides, and sesquiterpenes. As reported, Vernodalin is antiplasmodial; Vemonioside B1 is antiplasmodial and antischistosomal and Luteolin is a powerful antioxidant and anticancer [7-11]. From Hibiscus species, the extracts showed many activities including antibacterial, antioxidant, nephro-hepato-protective, renal/diuretic, anti-cholesterol, and antihypertensive and antidepressant effects [12,13]. Phenolic acids (e.g. protocatechic acid), organic acid (hydroxycitric acid and hibiscus acid) and anthocyanins (delphinidin-3-sambubioside and cyanidin-3-sambubioside) are likely to contribute to the reported effects. Garcinia species contain mainly flavonoids of the biflavonoid type; these flavonoids are thought to be responsible for the antihyperglycemic activity of its seeds $[14,15]$.

Some authors have demonstrated the antidiabetic activity of crude extracts and polyphenols of these plants in rats and mice. Few studies have investigated the hypoglycemic activity in rabbits. Rabbits are commonly used for screening prior to testing in a larger animal model. Many plants used in traditional medicine still need to be studied scientifically in order to verify their efficacy and standardize their pharmaceutical quality according to the actual content in bioactive compounds that can vary from soil to soil of cultivation. The aim of this study was to evaluate the antihyperglycemic activity of polyphenols and saponins extracts from the local species of these three plants.

\section{MATERIALS AND METHODS}

\subsection{Plant Materials}

Leaves of Vernonia amygdalina Delile (Va) and fruits of Hibiscus esculentus ( $\mathrm{He}$ ) and seeds of Garcinia kola were used (Fig. 1). Va-leaves and He-fruits were freshly harvested in Kisangani city; while Gk-seeds were bought at the big market of Kisangani, in the municipality of Makiso. 


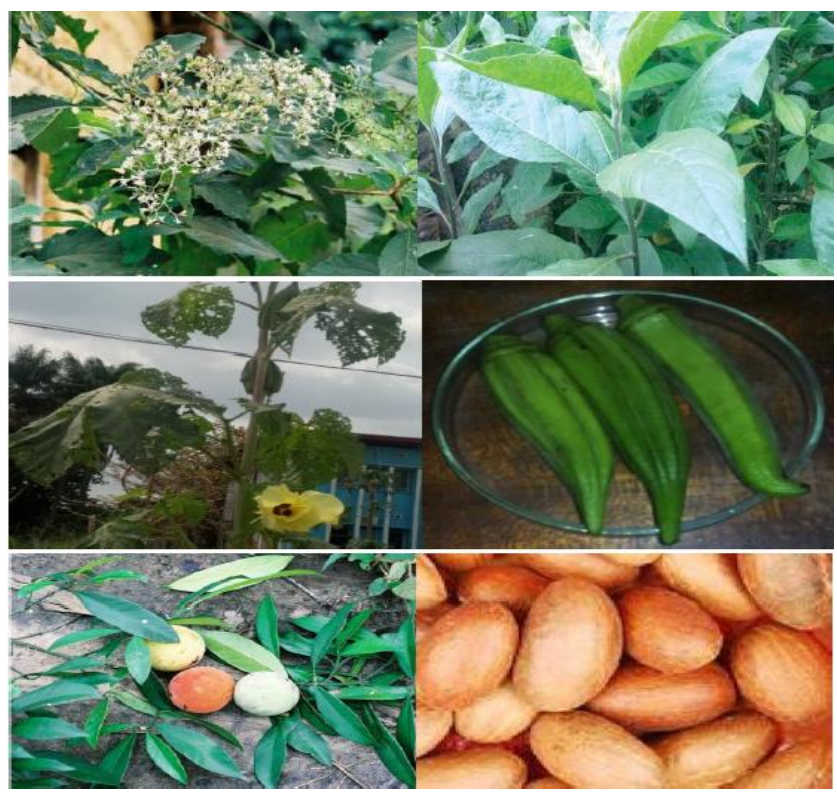

Fig. 1. Vernonia amygdalina (top), Hibiscus esculentus (middle) and Garcinia kola (bottom)

The botanical identity of the species harvested was confirmed by a botanist at the herbarium of the Faculty of Science of University of Kisangani.

$V$. amygdalina is a shrub 3 to $5 \mathrm{~m}$ high; the leaf is the edible part and used against diabetes in traditional medicine [16,17]. $H$. esculentus also called Hibiscus hispidissimus A. Chev or Abelmoschus esculentus (L.) Moench is a large annual cosmopolitan grass with erect stems up to 0.8 to $2.5 \mathrm{~m}$ high; the fruit is angular capsule, elongated, conical and pointed, 8 to $15 \mathrm{~cm}$ long; the green fruit is edible and used against diabetes [18]. G. kola also known as Garcinia dinklagei Engel., Garcinia courauana Engel., Garcina nitidula Engel., Garcinia giadidi De Wild, or in vulgar names of Small kola, Bitter-kola, False kolatier, can reach $20 \mathrm{~m}$ in height, giving yellow or orange globular or ovoid fruits containing 3 to 4 ellipsoid seeds; the seed is edible and used against diabetes in traditional medicine [19].

\subsection{Preparation of Plant Extracts}

The parts removed were shade-dried at room temperature in the laboratory before being transformed into powders and sieved on $1 \mathrm{~mm}$ mesh cloth. The extracts were prepared using adapted conventional methods [20-24].

Va-saponins fraction: Mix $20 \mathrm{~g}$ of the powder of leaves with $50 \mathrm{ml}$ hot methanol/water (30:70) solution. After cooling and decantation, filter and evaporate methanol. The aqueous phase is then mixed with equivalent volume of n-butanol, stirred and separated. The addition of diethyl ether into the n-butanol precipitates saponins. The precipitate is taken up with $40 \mathrm{ml}$ of distilled water and completed to $100 \mathrm{ml}$.

Va-butanol fraction: Boil (15 minutes) $20 \mathrm{~g}$ of the powder of the leaves in $100 \mathrm{ml}$ of water and filter on Whatman paper $n^{\circ} 3$; subject the filtrate to liquid-liquid extraction with n-butanol; evaporate the n-butanol extract to dryness, take up the residue with distilled water and bring the volume to $100 \mathrm{ml}$.

Va-ethanol fraction: Boil (15 minutes) $20 \mathrm{~g}$ of the powder of the leaves in $100 \mathrm{ml}$ of ethanol and filter on Whatman paper $n^{\circ} 3$; evaporate the ethanol extract to dryness, take up the residue with distilled water and bring the volume to 100 $\mathrm{ml}$.

Va-aqueous decoction 20\%: Boil (15 minutes) 20 $\mathrm{g}$ of the powder of the leaves in $100 \mathrm{ml}$ of water and filter on Whatman paper $n^{\circ} 3$; place the filtrate in a $100 \mathrm{ml}$ volumetric flask and bring to volume for immediate use.

He-decoction 20\%: Boil during 15 minutes $20 \mathrm{~g}$ of each finely ground fruits in $100 \mathrm{ml}$ of water and filter; place the filtrate in a $100 \mathrm{ml}$ volumetric flask and bring to volume for immediate use. 
Gk-decoction 20\%: Boil for 15 minutes $20 \mathrm{~g}$ of each finely ground seeds in $100 \mathrm{ml}$ of water and filter; place the filtrate in a $100 \mathrm{ml}$ volumetric flask and bring to volume for immediate use.

\subsection{Test of Antihyperglycemic Effect in Rabbits}

The protocol has been described elsewhere [2224]. Male rabbits aged 5 to 8 months weighing 1 to $1.8 \mathrm{Kg}$ were used. The animals lived at normal controlled temperature and photoperiod environment during 10-day acclimation period and the entire experimental period. Two days before the experimentation, they were divided into 8 groups of 5 rabbits each including: (1) Control, (2) Reference, (3) Va-ethanol, (4) Vabutanol, (5) Va-aqueous, (6) Va-saponin, (7) Heaqueous and (8) Gk-aqueous. The day of experiment, blood samples were taken by transverse incision of the marginal vein of the earlobe before the administration of the extracts (baseline T0). Then after, the control group received $1 \mathrm{ml}$ of water orally; the reference group received $1 \mathrm{ml}$ of glibenclamide $0.2 \mathrm{mg} / \mathrm{Kg}$; the test groups received orally $1 \mathrm{ml}$ of extract or 100 $\mathrm{mg} / 100 \mathrm{~g}$ body weight. Thirty minutes later, a second series of blood samples were taken before the administration of glucose (baseline T30); then after, all animals received glucose $50 \% \mathrm{w} / \mathrm{v}$ solution overload as $4 \mathrm{~g}$ per $\mathrm{Kg}$ of body weight. Other series of blood samples were collected hourly at T90, T150 and T210. The blood was collected directly on a test strip and the blood glucose read on the handheld Glucometer $\circledR$.

\subsection{Data Analysis}

The activity was expressed as percentage of change in glycemia (PRG) on the basis of negative control according to the following formula:

$$
P R G=100 . \frac{(\text { Gcontrol }- \text { Gextrait })}{\text { Gcontrol }}
$$

The values were calculated as mean \pm ESM (Standard Error on Mean). The treatment of data was carried out with Excel Windows software using 'ANOVA' and Tukey's post hoc test for significance at $95 \%$ confidence limit.

\section{RESULTS}

The extraction yielded $6.95 \pm 0.89 \%$ of $\mathrm{Va}$ ethanolic extract, $6.8 \pm 0.6 \%$ of $\mathrm{Va}$-aqueous extract, $2.85 \pm 0.08 \%$ of n-butanolic extract and 4 \pm 0.5 of Va-saponin extract. Fig. 2 presents the evolution of glycemia in time for different experimental groups.

As shown, the baseline values before the extracts were administered were slightly reduced or almost unchanged 30 minutes after in Vaethanol, Va-aqueous, Va-butanol, Gk-aqueous and He-aqueous groups while the glycemia was however significantly $(p<0.05)$ increased by $\mathrm{Va}$ saponins from 98 to $244 \mathrm{mg} / \mathrm{dL}$. After glucose overloading, the peak of glycemia appeared at 1 hour (T90) reaching the values of $308.5 \pm 1.2$ for negative control, 292.0 \pm 5.1 Va-butanol, $161.2 \pm 3.6$ for Va-aqueous, $158.2 \pm 5.1$ for $\mathrm{Va}$ ethanol, 201.3 \pm 9.4 for He-aqueous, $276.2 \pm 30.4$ for Gk-aqueous, and 105.5 \pm 6.7 for glibenclamide.

Table 1 shows the AHGA values as PRG at T210 time. They varied from $42.5 \%$ for Va-butanol to $70.5 \%$ for Va-ethanol. The mean value of glycemia at T210 observed in Va-saponins group was superior to that produced in the control group (287 vs. 268). The effect of Va-ethanol extract was relatively $17 \%$ higher than the effect of the reference drug $(R=1.17)$.

\section{DISCUSSION}

The findings from the current study have shown the capacity of tested extracts to significantly $(p<0.01)$ reduce induced hyperglycemia in rabbits, at the exception of the saponins extract. At equivalent doses, Va-ethanol extract was the most active $(70 \%)$ compared to $\mathrm{V}$-aqueous and Va-butanol. The ethanolic extract induced an intense and prolonged activity superior to that of glibenclamide.

At the equivalent doses used, GK-aqueous activity is comparable to Va-butanol and less than the activity of He-aqueous. They take longer to lower blood glucose compared to Va-ethanol; this may relate to the speed of absorption.

The Va-saponins extract seemed inactive or capable of elevating blood sugar instead of reducing. However, the study by Okodowa et al. [25] showed antidiabetic effect of Vernonia amygdalina leaf $n$-butanol extract containing mainly saponins in fortified diet-fed streptozotocin-treated rat model of type-2 diabetes. Some saponins like ginsenoside isolated from the roots of Panax ginseng, and diosgenin isolated from Trigonella foenum- 

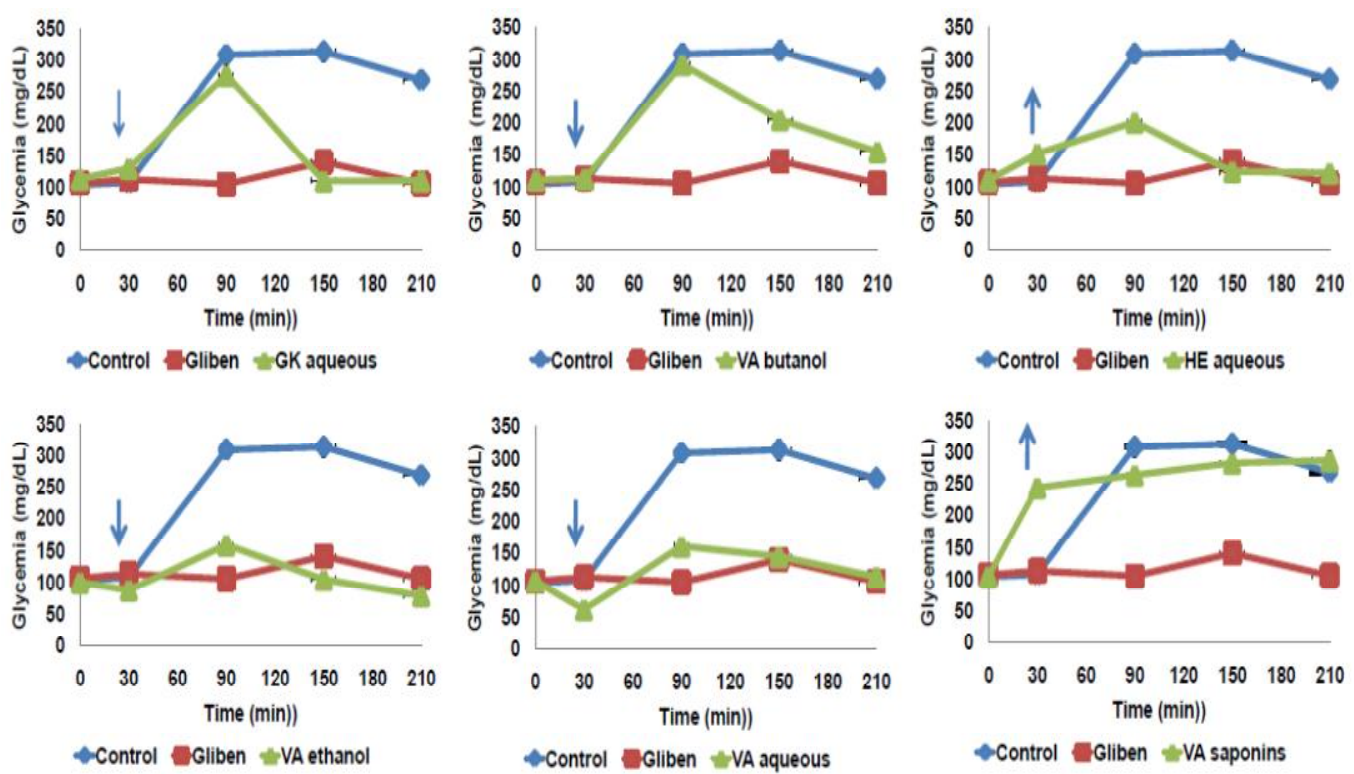

Fig. 2. Effect of various extracts on induced hyperglacemia compared to control and gliben

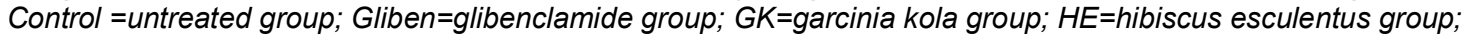
$V A=$ vernonia amygdalina group. The values are means of 5 animals. The extracts $(100 \mathrm{mg} / \mathrm{Kg})$ and glibenclamide $(0.2 \mathrm{mg} / \mathrm{Kg})$ were administered at TO and glucose $(4 \mathrm{~g} / \mathrm{Kg})$ at $T 30$

Table 1. Mean antihyperglycemic activity

\begin{tabular}{llll}
\hline & T210 & PRG(T210) & Ratio \\
\hline Control (negative) & $268.2 \pm 10.3$ & 0 & \\
Glibenclamide & $106.0 \pm 2.5$ & 60.5 & 1.00 \\
Va-ethanol & $79.2 \pm 2.0$ & 70.5 & 1.17 \\
Va-aqueous & $113.6 \pm 3.5$ & 57.6 & 0.95 \\
Va-butanol & $155.0 \pm 3.7$ & 42.2 & 0.70 \\
Va-saponins & $287.0 \pm 2.0^{*}$ & $-7.0^{*}$ & \\
He-aqueous & $122.0 \pm 8.6$ & 54.5 & 0.90 \\
Gk-aqueous & $110.7 \pm 7.1$ & 58.7 & 0.97 \\
\hline
\end{tabular}

Percentage of change in glycemia (PRG) *Value > control

Graecum have been found endued of antihyperglycemic activity [26-28] contrary to our findings. Even though saponins do not influence blood sugar levels in glucose tolerance protocol, their property of reducing the level of triglycerides and cholesterols in the blood is recognized by virtue of their surfactant property. Some studies have found a significant decrease in weight gain induced by raw saponins of $V$. amygdalina leaves in rat [29].

The chemical compounds holding this activity were not determined in this study but may be similar to those described elsewhere in the literature [Fig. 3].

For Vernonia species, a number of biologicallyactive compounds have been found in Va-leaves
[10,11,30-33]. Vernodalin (sesquiterpene lactone), vernonioside B1 (saponoside) and luteolin (flavonoids) are among the active compounds. As already mentioned, vernodalin is antiplasmodial; vemonioside B1 is antiplasmodial and antischistosomal, and Luteolin is a powerful antioxidant and anticancer [30-33]. The precise active ingredient responsible for the antidiabetic is still unknown. Furthermore, the Va-leaves contain about ten amino acids including arginine [34]. It is also possible that these amino acids have a direct influence on blood glucose levels. Arginine has been found hypoglycemic in mice lacking GLP-1 receptors by improving the sensitivity of cells to insulin [35]. It is also known that the regular consumption of dietary fibers is linked to the increase in the synthesis of GLP-1, a hormone made in the 


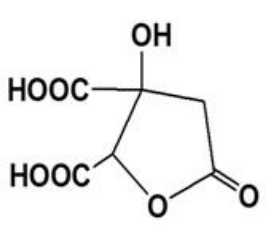

hibiscus acid
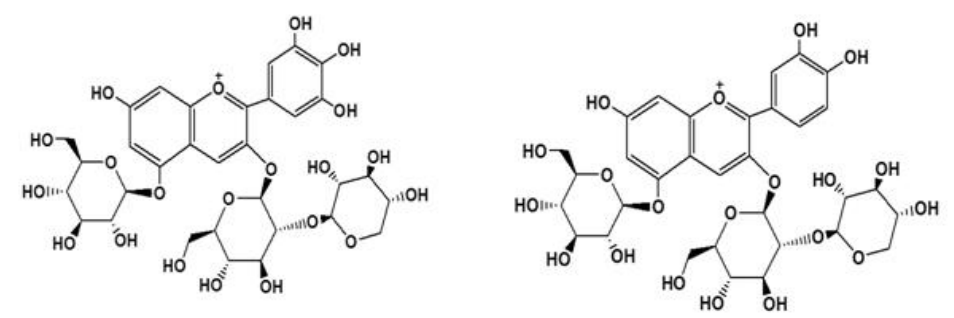

delphinidin-3-sambubioside and cyanidin-3-sambubioside
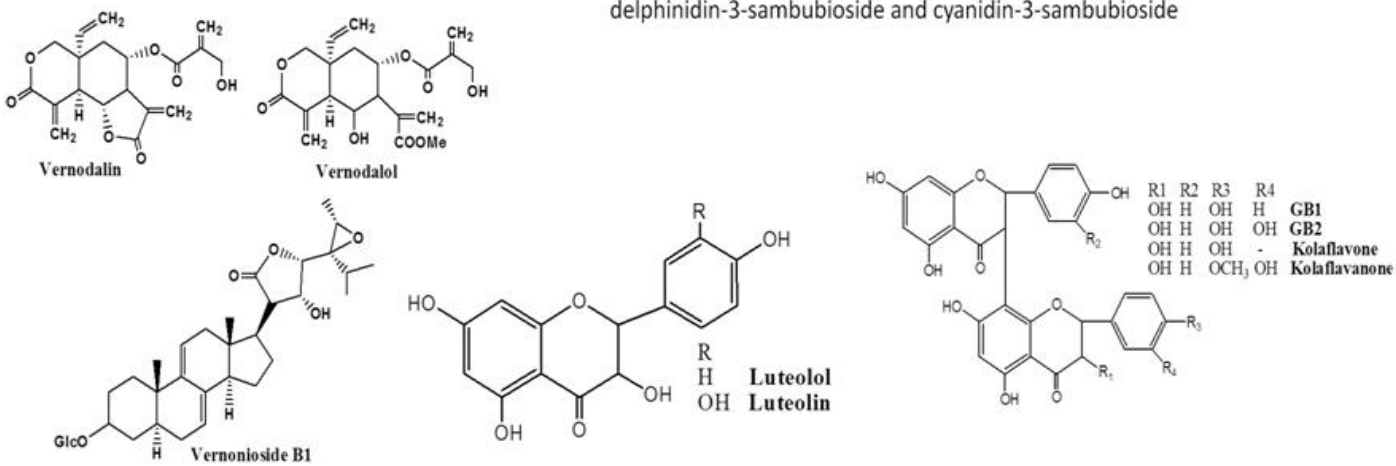

Fig. 3. Some secondary metabolites from $V$. amygdalina, $H$. esculentus, $G$. kola species

intestine that induces $70 \%$ of the insulin released after ingestion of dietary carbohydrates [35,36]. In addition, an amino acid, 4-hydroxyisoleucine extracted from Fenugreek seeds stimulates the secretion of glucose-dependent insulin, decreases insulin resistance and inhibits hepatic glucose release [28].

For Hibiscus species, the activity might be linked to strong antioxidant activity, inhibition of alphaglucosidase and alpha-amylase, inhibition of angiotensin-converting enzyme (ACE), and direct vaso-relaxant effect or calcium channel modulation. The species contains mucilage as the major active ingredient $[12,13]$. This soluble fiber is a very hydrophilic heterogeneous polysaccharide which would be responsible for antihyperglycemic activity by reducing the rate of absorption of carbohydrates in the intestine. Phenolic acids (e.g. protocatechic acid), organic acid (hydroxycitric acid and hibiscus acid) and anthocyanins (delphinidin-3-sambubioside and cyanidin-3-sambubioside) are likely to contribute to the reported effects $[12,13]$.

Studies on Gk report that aqueous decoction of Gk contains mainly flavonoids of the biflavonoid type. These flavonoids are thought to be responsible for the antihyperglycemic activity of Gk seeds $[10,14,15]$.

Finally, the findings concern total extracts and should not extrapolated to the potential pure compounds. Improved tradimedicines that can be prepared with these extracts shall be standardized and validated according to pharmaceutical requirements.

\section{CONCLUSION}

The purpose of this study was to compare the antihyperglycemic activity of different extracts of three plants, identify the most active plant and the phytochemical group responsible for this activity, in light of the chemical composition of each extract. All extracts have a relative activity comparable to glibenclamide with the exception of Va-saponins. Improved tradimedicines can be prepared with ethanolic or total polyphenolic dry extracts.

\section{CONSENT}

It is not applicable.

\section{ETHICAL ISSUES}

The study protocol was approved by the ethical committee of the University FMP 130/2016 and fulfilled the requirements of EEC Directive applicable to animal experiment.

\section{COMPETING INTERESTS}

Authors have declared that no competing interests exist. 


\section{REFERENCES}

1. Frank B. Hu. Globalization of diabetes. Available:http://care.diabetesjournals.org/c ontent/34/6/1249

2. Sena CM, Bento CF, Pereira P, Seiça R. Diabetes mellitus: New challenges and innovative therapies. EPMA J. 2010;1(1): 138-163.

3. Rawal LB, Tapp RJ, Williams ED, Chan C, Yasin S, Oldenburg B. Prevention of type 2 diabetes and its complications in developing countries: A review. Int J Behav Med. 2012;19(2):121-33.

4. Gupta RC, Chang D, Nammi S, Bensoussan A, Bilinski K, Roufogalis BD. Interactions between antidiabetic drugs and herbs: An overview of mechanisms of action and clinical implications. Diabetology \& Metabolic Syndrome. 2017;9:59.

5. Yatoo MI, Saxena A, Gopalakrishnan A, Alagawany M, Dhama K. Promising antidiabetic drugs, medicinal plants and herbs: An update. International Journal of Pharmacology. 2017;13:732-745.

6. Desai S, Tatk P. Charantin: An important lead compound from Momordica charantia for the treatment of diabetes. Journal of Pharmacognosy and Phytochemistry. 2015;3(6):163-166.

7. Ota A, Ulrih NP. An overview of herbal products and secondary metabolites used for management of type 2 diabetes. Front Pharmacol. 2017;8:436.

8. Katemo M, Mpiana PT, Mbala BM, Mihigo SO, Ngbolua KN, Tshibangu DST, Koyange PR. Ethnopharmacological survey of plants used against diabetes in Kisangani city (DR Congo). Journal of Ethnopharmacology. 2012;144:39-43.

9. Mohammed A, Kumar D, Rizvi SI. Antidiabetic potential of some less commonly used plants in traditional medicinal systems of India and Nigeria. J Intercult Ethnopharmacol. 2015;4(1):78-85.

10. Farombi EO, Owoeye O. Antioxidative and chemopreventive properties of Vernonia amygdalina and Garcinia biflavonoid. Int J Environ Res Public Health. 2011;8(6): 2533-2555.

11. Adeolu AA, Olujoke JA, Ademola AO. Anti-oxidant, anti-inflammatory and antinociceptive properties of the acetone leaf extract of Vernonia amygdalina in some laboratory animals. Adv Pharm Bull; 2014. Available:www.ncbi.nlm.nih.gov
12. Gul MZ, Bhakshu LM, Ahmad F, Kondapi AK, Qureshi IA, Ghazi IA. Evaluation of Abelmoschus moschatus extracts for antioxidant, free radical scavenging, antimicrobial and antiproliferative activities using in vitro assays. BMC Complementary and Alternative Medicine. 2011;11.

13. Doreddula SK, Bonam SR, Gaddam DP, Rao Desu BS, Nadendla Ramarao N, Pandy V. Phytochemical analysis, antioxidant, antistress, and nootropic activities of aqueous and methanolic seed extracts of ladies finger (Abelmoschus esculentus L.) in mice. The Scientific World Journal; 2014.

Available:http://dx.doi.org/10.1155/2014/51 $\underline{9848}$

14. Adaramoye OA. Antidiabetic effect of kolaviron, a biflavonoid complex isolated from Garcinia kola seeds, in wistar rats. Afr Health Sci. 2012;12(4):498-506.

15. Ofor CC, Oguwike FN, Onubueze DPM, Olisa MC. Effects of bitter Kola (Garcinia kola) on haemostatic and biochemical induced male diabetic albino wistar rats. Journal of Dental and Medical Sciences. 2013;11(3):53-57.

16. PROTA.

Available:http://uses.plantnetproject.org/en/Vernonia amygdalina (PR OTA)

17. Clement E, Erharuyi O, Vincent I, Joy A, Christopher A. Significance of bitter leaf (Vernonia amagdalina) in tropical diseases and beyond: A review. Malar Chemoth Cont. 2014;3:120.

18. Genus: Hibiscus L.

Available:https://web.archive.org/web/2010 0528145907/http:/www.ars-grin.gov/cgibin/npgs/html/genus.pl?5665

19. Udenze ECC, Braide VB, Okwesilieze CN, Akuodor GC. Pharmacological effects of Garcinia kola seed powder on blood sugar, lipid profile and atherogenic index of alloxan-induced diabetes in rats. Pharmacologia. 2012;3(12):693-699.

20. Lejoly J, Ndjele MB, Geerinck O. Catalogue-flore des plantes vasculaires des districts de Kisangani et de la Tshopo (RD Congo). Taxonomania. Revue de Taxonomie et de Nomenclature Botaniques. 2010;30:1-307.

21. Mangambu M, Mushagalusa KF, Kadima NJ. Contribution to phytochemical study of some antidiabetic plants from Bukavu and 
surrounding (South Kivu, DR Congo). Journal of Applied Biosciences. 2014;75: 6211-6220.

22. Katemo F, Kadima NJ, Marini RD. Comparative phytochemical composition and hypoglycemic activity of some plants used by traditional healers to treat diabetes in Kisangani. International Journal of Pharmacy and Pharmaceutical Research. 2017;9(4):312-321.

23. Katemo MF, Kadima NJ, Ranarivelo $\mathrm{N}$, Frédérich $M$, Hubert $P$, Marini RD. Preliminary phytochemical content and antidiabetic potential investigations of Panda oleosa (Pierre) used in Kisangani areas. American Journal of Analytical Chemistry. 2017;8(9):564-581.

24. Mushagalusa KF, Wendo FM, Muyisa SK, Kadima NJ. Comparative hypoglycemic activity of flavonoids and tannins fractions of Stachytarpheta indica (I.) Vahl leaves extracts in guinea-pigs and rabbits. ljppr. 2016;5(2):48-57.

25. Okoduwa SIR, Umar IA, James DB, Inuwa $\mathrm{HM}$. Validation of the antidiabetic effects of Vernonia amygdalina Delile leaf fractions in fortified diet-fed streptozotocin-treated rat model of type-2 diabetes. Journal of Diabetology. 2017;8(3):74-85.

26. Keller AC, MA J, Kavalier A, He K, Brillantes AM, Kennelly EJ. Saponins from the traditional medicinal plant Momordica charantia stimulate insulin secretion in vitro. Phytomedicine. 2011;19(1):32-37.

27. Goyal S, Gupta N, Chatterjee S. Investigating therapeutic potential of Trigonella foenum-graecum L. as our defense mechanism against several human diseases. J Toxicol. 2016;1250387. DOI: $\underline{10.1155 / 2016 / 1250387}$

28. Neelakantan NL, Narayanan M, de Souza RJ, van Dam RP. Effect of Fenugreek (Trigonella foenum) intake on glycemia: A meta-analysis of clinical trials. Nutr. J. 2014;18:13-7.

29. Adaramoye OA, Akintayo O, Achem J, Fafunso MA. Lipid lowering effects of methanolic extracts of Vernonia amygdalina leaves in rats fed on high cholesterol diet. Vasc Health Risk Manag. 2008;4(1):235-41.

30. Erasto G, Grierson DS, Afolayan AJ. Bioactive sesquiterpene from leaves of Vernonia amygdalina. J. Ethnopharmacol. 2006;106:117-129.

31. Ngbolua KN, Rakotoarimana H, Rafatro, Ratsmana UV, Mudogo V, Mpiana PT. Comparative antimalarial and cytotoxic activities of two Vernonia species: $V$. amygdalina from Democratic Republic of Congo and V. cinerea subspvialis endemic to Madagascar. International Journal of Biological and Chemical Sciences. 2011;5: 345-353.

32. Cimanga RK, Tona L, Mesia K, Musuamba CT, de Bruyne T, Apers S, Hernan N, Miert VS, Pieters L, Totte J, Vlietink AJ. In vitro antiplasmodial activity of extracts and fractions of seven medicinal plants used in the Democratic Republic of Congo. J. Ethnopharmacol. 2004;93:27-32.

33. Muraina IA, Adaudi AO, Mamman $M$, Kazeem HM, Picard J, Mcgaw LJ, Eloff JN. Antimycoplasmal activity of some plant species from northern Nigeria compared to the currently used therapeutic agent. Pharm. Biol. 2010;48:1103-1107.

34. Usunobun U, Ngozi P. Phytochemical analysis and proximate composition of Vernonia amygdalina. International Journal of Scientific World. 2016;4(1):11-14.

35. Claybaugh T, Decker S, McCall K, Slyvka Y, Steimle J, Wood A, Schaefer M, Thuma $\mathrm{J}$, Inman S. L-arginine supplementation in type II diabetic rats preserves renal function and improves insulin sensitivity by altering the nitric oxide pathway. International Journal of Endocrinology; 2014.

Available:http://dx.doi.org/10.1155/2014/17 1546

36. El-Abhar HS, Schaalan MF. Phytotherapy in diabetes: Review on potential mechanistic perspectives. World J Diabetes. 2014;5(2):176-197. DOI: $\underline{10.4239 / \text { wjd.v5.i2.176 }}$

(C) 2018 Katemo et al.; This is an Open Access article distributed under the terms of the Creative Commons Attribution License (http://creativecommons.org/licenses/by/4.0), which permits unrestricted use, distribution, and reproduction in any medium, provided the original work is properly cited.

Peer-review history:

The peer review history for this paper can be accessed here: http://www.sciencedomain.org/review-history/23825 